\title{
SINGULARIDADE DOS SUJEITOS NA VIVÊNCIA DOS PAPÉIS SOCIAIS ENVOLVIDOS NA HOSPITALIZAÇÃO
}

\author{
Eliane Corrêa Chaves* \\ Cilene Aparecida Costardi Ide*
}

CHAVES, E.C.: IDE. C.A.C. Singularidade dos sujeitos na vivência dos papéis sociais

envolvidos na hospitalizaçáo. Rev.Esc. Knf.US'P. v.29. n.2.p.173-79, ago. 1995.

O estudo apresenta uma análise das emoções, dos sentimentos e dos comportamentos que resultaram da relação enfermeira-paciente-familiar durante um processo de hospitalização $e$ de suas conseqüencias para cada um dos grupos envolvidos.

I.NITERMOS: Hospitalização. Papéis sociais.

Muito do que tem sido estudado a respeito da vivência da hospitalização tem convergido para a análise do sofrimento do doente decorrente da crise orgânica. das ameaças. dos medos. da sensacão de vulnerabilidade diante da impossibilidade de controle solore seu corpo. sua vontade e seu destino. ()utra vertente de análise tem apontado para as conseqüencias do processo de hospitalização prop riamente dito, ou seja, do modo como os rituais. as imposições. as regras, o controlo sobreo comportam ento dos doentes sulımetidos a rígida estrutura hospitalar agride o seu psiquismo, intensificando o sofrimento inerente ao desequilíbrio orgânico inicial.

A convergência dessas duas vortentes associadas ao fato de que a internação implica em ruptura brusea e radical com seu cotidiano. resulta em mais uma possibilidade de analise da questão, agora relacionada respecificamente com a desestruturação, ou ate mesmo supressão dos antigos papéis sociais desempenhados polo doente e a assunção de novos processos. Esse processo pode ser visto. em última insiancia como uma descaracterizaça dos vínculos sociais e afetivos vigentes, o que impliearáa na melhor das hipóteses em sofrimento psíquice e em crise de identidade.

\footnotetext{
*Professores-Doutores do Departamento de Enfermagem Médico-Cirúrgica da Escola de Enfermagem da USP.
} 
Os desdobramentos que ocorrem a partir de então permeiam, com maior ou menor intensidade, as concepçôes e as emoções do doente, modificando suas relações interpessoais no interior dos diferentes grupos sociais a que pertence além de alterar suas relações consigo mesmo, resultando em abalo da auto-estima e da auto-concepcão de uma forma geral.

De qualquer modo quando se analisa o processo de hospitalização. mesmo que o enfoque seja o doente, corre-se o risco de distorcer a análise caso não se considere o interjogo que se configura no decorrer da hospitalização a partir da confluência dos papéis que aí estão envolvidos.

Em outras palavras, mesmo que, em tese, a meta central de uma internação seja o atendimento ao doente, sob a otica dos papéis sociais, os objetivos dos sujeitos nem sempre são completamente coincidentes. vel afirmar, inclusive, que o processo de hospitalização constitui-se numa vivência de significados diferentes, em alguns aspetos, inclusive opostos, para os sujeitos que dele participam. Essas diferenças de significados possibilitam o surgimento de concepcōes e atitudes distintas diante da mesma situação, o que poderá implicar em equívocos de julgamento em relação ao outro, gerando impossibilidade de empatia, insatisfações, inseguranças, isolamento e ate. mesmo tendências paranóides.

Centrando nossa análise unicamente no "papel do paciente" e no "papel do enfermeiro" temos que para o primeiro. a hospitalizaça constitui-se num momento peculiar de descontinuidade no trajeto dos diferentes papéis que desempenha na vida e dos projetos que estabeleceu para si. li um estado de ruptura com a essência singular do sujeito, onde a imposição e a coerção estão presentes desde a opção pela internação, até o momento da alta.

No que se refere ao enfermeiro, o significado da hospitalizaçăo foxalamente oposto, isto 6, não há ruptura e sim continuidade do seeu projeto de vida profissional. Não altera os papéis sociais que desempenha, ao contrário. os reforça na medida em que afirma sua identidade profissional e seus desdobramentos.

Para o paciente a internação freqüentemente o vista e sentida como algo transitório; um mal necessário que permitirá seeu retorno a um estado de saúde compatível com sua vida cotidiana. Na busca desse objetivo submete-se a sofrimentos de diversas naturezas, e para suportá-los, lança mão de mecanismos de defesa característicos de pessoas ameaçadas mas ao mesmo tempo subjulgadas e impotentes diante do agente ameaçador.

Para a enfermeira, o processo de internação pode ser sen tido como um momento de ameaça ao seu cotidiano já conhecido e de certa forma. controlado. $\Lambda$ cada nova internação a enfermeira se vê diante de novas demandas trazidas pelas características de personalidade do doente dos familiares e pela exigência técnica da própria doença as quais, muitas vezes, não se sente 
apta a atender. Diante dessa situação, a enfermeira também utilizará mecanismos de defesa os quais, no entanto, serão distintos daqueles utilizados pelos pacientes pois, embora em ambos os casos os sujeitos percebem o perigo, no caso específico da enfermeira ela identifica possibilidades de neutralizálo.

Surge, portanto, mais um objetivo a ser alcançado no decorrer da hospitalização, ou seja: mobilizar recursos internos para enfrentar as ameaças identificadas. Este segundo objetivo, a princípio, não caracteriza-se como obstáculo para a consecução do primeiro, no entanto, pode dificultá-lo consideravelmente na medida em que o substrato psíquico dos sujeitos envolvidos não constituí-se em um suporte eficaz para a avaliação e para o enfrentamento de situações ameaçadoras. Nesse caso, o sujeito pode inverter as prioridades dos objetivos e agir, mesmo que inconscientemente, muito mais no sentido de neutralizar os riscos identificados e diminuir sua própria ansiedade do que atender as necessidades do doente.

No decorrer de três anos consecutivos, alunas da disciplina de Enfermagem Medico-Cirúrgica da Escola de Fnfermagem da USP desenvolveram três trabalhos diferentes que tiveram o objetivo de investigar consecutivamente a vivência da hospitalização sob a btica do paciente ${ }^{4}$ da família ${ }^{2}$ da enfermeira ${ }^{3}$. Embora os dados tenham sido colhidos em epocas distintas, os grupos pesquisados pertenciam ao mesmo universo organizacional. $\Lambda$ metodologia utilizada tambem foi semelhante em todos eles e baseou-se na análise do conteúdo dos discursos dos componentes dos grupos em questão, buscando possibilitar a expressão da livre associação de ideias. Por meio dos conteúdos obtidos nos três trabalhos foi possível identificar categorias de análise que representavam o produto da relação simbolico-cognitivo-afetiva que as pessoas entrevistadas estabeleciam entre si e seus papois.

() trabalho aqui apresentado constitui-se na confluência do conteúdo obtido a partir dos três grupos estudados anteriormente e tem por objetivo analisar o interjogo que se configura a partir da convivência de grupos com papeis sociais diferentes diante de uma situação basicamente comum, além de reconhecer o movimento cognitivo e afetivo que apresentam para superar ou conviver com situações adversas.

()s discursos obtidos permitiram o delineamento de concepções, percepçôes e reações apresentadas pelos sujeitos analisados. Entre os pacientes foi signilicativa a atitude passiva e aparentemente resignada em relação ao poder, no que diz respeito ao erro, a negligência, a desinformação, a impessoalidade, a desatenção e ao desafeto nas relações. (Os pacientes demonstraram tendência a estabelecer uma relação até certo ponto paradoxal com o poder, na qual se evidencia o reconhecimento da perda de autonomia sobre si e sobre a situação vivenciada. () comportamento submisso foi o mais freqüente, manifestou-se explicitamente e foi reforçado pela tendência a 
fragilização e à infantilização que a própria doença desencadeia. Subjacente a ele foi possivel perceber, embora de forma velada, comportamentos relacionados à rejeição, antipatia e até mesmo desprezo pela autoridade, manifestas por meio de mecanismos elementares de burla das regras, seja por atitudes pessoais travestidas de ingenuidade ou desinformação, seja pela utilização de argumentos de persuasão a terceiros.

O sof rimento físico decorrente da doença, (vivido concretamente ou por meio de pensamentos fantasiosos), somado ao sofrimento psíquico resultante. de doença e do próprio processo de hospitalização conduziram alguns pacientes a pensamentos persecutorios e manifestaçôes paranóides que intensificaram seu sofrimento. Constituiu-se, a partir de então. um círculo vicioso que os pacientes demonstraram grande dificuldade de romper sem ajuda.

O papel da família, neste cenário pareceu apresentar características variáveis que, ora demonstraram maior aderência à realidade do donnte, ora aproximaram-se dos representantes do poder institucional. ()s familiares. na maioria das vezes, compartilharam do sofrimento do doente e em muitas situações sofreram com ele, no entanto. por não estarem submetidos a internação, por não vivenciarem a coerção, a infantilização $C$ a agressão psicologica inerentes ao fato de estar submetido a uma instituição total. não identificaram como tal os mecanismos de defesa que o doente utilizou. Não reconheceram a necessidade do paciente defender-se, até porque. segundo suas crenças, "aqui, tudo e feito para seu bem, fe necessário para sua recuperação". Diante disso, os comportamentos defensivos dos pacientes foram. muitas vezes, interpretados como "manha", medo, teimosia o a partir dessa interpretação, os familiares tenderam a agir segundo os padróes ditados polos sujeitos da instituição. ou seja. omitiram informações aos doentes. minimizaram os riscos a que foram expostos, usaram os mais variados métodos de persuasão para que o paciente não colocasse obstáculos ao tratamento.

Em outros momentos, em nome do vínculo afolivo que os unia acs doentes tentaram minimizar o seu sofrimento através da atenção aos seus apelos. Nesse momento, geralmente lançaram mão da sedução. do suborno e da burla para atenuar a forca do poder institucional e satisfazer algumas demandas do paciente.

Este jogo de forças de interesses a que o familiar foi submetido, mostrou-se penoso e bastante perverso, uma vez que, na grande maioria das vezes, o familiar agiu de acordo com o critério e com os interesses de outros. o que resultou em dúvidas, conflitos, incertezas e culpas.

As enfermeiras, por outro lado, vivenciaram a hospitalizaça sobre uma otica bastante peculiar e distinta da que vimos até agora, pois estavam expostas a ameacas especificas, inerentes a estrutura organizacional e ao processo de trabalho a que estão submetidas. 
$\Lambda$ ansiedade que daí resultou demandou portanto meios especificos de controle.

Segundo BORZO) (1992), a repercussão do trabalho da enfermeira sobre sua saúde mental pode determinar comportamentos que considerou indicativos de sofrimento psíquico. Ainda segundo a autora, um dos prineipais motivos para esse sofrimento seria o sentimento persecutório gerado pela imprevibilidade das conseqüencias do seu trabalho, para si e para o doente. em virtude de estarem à mercê da administração do hospital: pela impossibilidade de assegurar a recuperação do paciente e pela subordinação do seu trabalho ao poder médico. () comportamento defensivo diante disto manifesta-se pelo uso demasiado da vigilância dirigida aos fatos, aos sujeitos e as coisas que compõem seu cotidiano de trabalho, com o objetivo de evitar a perda de controle. a culpa e a punição. Diante deste cenário, situações novas podem significar ameaças, na medida em que envolve sujeitos e fatos desconhecidos a princípio, e portanto fora de controle.

A análise do processo de hospitalização deste estudo desvendou dois significados básicos para as enfermeiras. Um deles vinculado ao início da internação, ou seja, ao momento de introdução do doente na instituição. () out.ro relacionou-se a fases posteriores a essa. na qual deu-se o desvendamento do doente como pessoa e a aceitação, por parte deste, das regras. normas e rotinas do hospital. Esta fase corresponderia à transformação do doente em paciente.

Na primeira fase do processo de internacão foi possível perceber um grande interesse da enfermeira em aproximar-se do doente. em colher informações relativas a seeus hábitos . suas dificuldades, etc... Muitas vezes. para obter essas informaçoes solicitaram inclusive a ajuda da família. A partir de então seguiu-se a fase de orientaçoes relativas à clínica, na qual o doentes tomaram conhecimento do modo como deveriam agir para se manterem consonantes com a dinâmica institucional. At. esse momento. por ter havido a presença fisica marcante da enfermeira diante de uma situação que o doente não qualificara como muito importante pois não existiam demanda relacionada ao agravamento de seu estado de saúde. eles foram induzidos a supor que no momento "realmente necessário" para ele, a disponibilidade e interesse da enfermeira seriam ainda maiores. Nessa fase sentiram-se seguros e agradecidos e. geralmente, demonstraram enfaticamente seus sentimentos. As enfermeiras, por sua vez, demonstraram acreditar sinceramente. que os dados que colheram dos doentes seriam necessários para qualificar a assistência a ser prestada. Demonstraram ainda. satisfaça com a amabilidade do doente uma vez que pereeheram. nessa atitude. a possibilidade de reconhecimento de seu trabalho. Pudemos perceber portanto, que, nessa fase estabeleceu-se um contrato velado, no qual a enfermeira comprometeu-se 
com o doente a manter a dedicação e o interesse demonstrados até esse momento e o doente comprometeu-se com a enfermeira em demonstrar seu reconhecimento.

Na segunda fase do processo de internação no entanto. foi possível perceber, de uma forma abrupta e quase absoluta, a quebra desse "contrato inicial" . A enfermeira, por ter controlado a ansiedade gerada pela ameaça do "novo" passou a atender o doente com hase nas demandas l'isicas que ela ou a equipe medica julgaram prioritárias o que em vários casos significou a um afástamento físico ou pelo menos afetivo do doente. ()s pacientes por sua vez, por sentirem-se inseguros a abandonados e, muitas vezes, por não se sentirem dispostos fisicamente não conseguiram manter a gentilezal que de. monstram inicialmente. Lim alguns momentos inclusive. relacionaram-se friamente com a enfermeira e muitas vezes, mesmo que de maneira velada. eshoçaram comentários que denotaram insatisfação com a assistência que estavam recebendo e seu descredito em relaça à competência profissional da enfermeira.

Portanto, por motivos diversos e distintos tanto o paciente idealizou a assistencia que iria receber. como a enfermeira idealizou a assistência que poderia prestar. () contrato simbólico que se estabeleceu nos primeiros contatos induziu o paciente a acreditar que seria único e especial para a enfermeira e que todas as suas necessidades seriam allendidas. Ao mesmot tempo. induziu a enfermeira a agir como se tivesse possibilidade de corresponder aos anseios do doente. Ambos basearam suas atiludes na absoluta impotência do doente e na onipotência da enfermeira.

No decorrer da internação a realidade se sobrepôs a cssa idealizaçã: no entanto. como este contrato simbólico teve en sua base demandas afetivas e subjetivas, a reação a sua quebra não poderia ser produto da esfera da razão e por isso. tende a ser vivida como foi por ambos os sujeitos. como cisão traição. Por resultarem da mobilização de afetos e moçons. as respostas comportamentais tendem a ser muito mais defensivas do que resolutivas.

$\Lambda \mathrm{mbos}$ os sujeitos sentir-so-ão traídos. injustiçados e al)andonados. o que provavelmente implicará em maior sofrimento o exacerlação dos comportamentos defensivos. Para o doente, isso implicará numa dolorosa experiencia mas que apos a internação, tende a perder-se na sua memória à medida que ele recupera seu cotidiano escus papeis sociais. Para a enfermeira. as implicaçōes serão muito mais sérias a medida que esses comportamentos defensivos caracterizam seu cotidiano de tral)alho e por tenderem a tergiversação de um círculo vicioso hostil. e conseqüente sofrimento psíquico que pode, inclusive culminar em somatizações. 
CHAVES, E.C.; IDE, C.A.C. Social roles and hospitalization. Rev.Esc.Enf.USP, v.29, n.2. p.173.79, aug. 1995.

The research brings a emotions, behaviorsand feelings analysis of the nurses, patients and parents relationship that occurs during the hopitalization, and shows the consequence of this for all envolved persons.

INITERMOS: Hospitalization. Social role.

\section{REFERÊNCIAS BIBLIOGRÁFICAS}

1. BORZOI, I.C.F. Saúde mental e trabalbo: um estudo de caso da enfermagem. Sáo Paulo. 1992. 97 p. Dissertaçáo (Mestrado). Instituto de Psicologia, Pontificia Universidade Católica.

2. CAMARGO, R B et al. A resposta dos familiares frente ao processo de hospitalizaçăo, Sao Paulo. Departamento de Enfermagem Médico-Cirúrgica, 1991. /mimeografado/.

3. ELIAS. N. et al A vivéncia do processo de hospitalizaçáo sob o prisma do enfermeiro, Sáo Paulo. Departamento de Enfermagem Médico-Cirúrgica, 1992. /mimeografado/.

4. MAzZOTTI, M.R. et al. O processo de hospitalizaçáo sob a ́́tica do docente. Sao Paulo. Departamento de Enfermagem Médico-Cirúrgica, 1993. /mimeografado/. 